\title{
THE EFFECTS OF INHALATION ANAESTHETIC AGENTS ON CONVULSANT (LD-50) DOSES OF LOCAL ANAESTHETICS IN THE RAT
}

\author{
John A. Staniweski, B.A. and J. Antonio Aldrete, M.D. ${ }^{*}$
}

The InITIAL studies dealing with attempts to prevent the central nervous system toxicity observed after overdosage of local anaesthetic drugs were done in 1926 by Tatum, Atkinson, and Collins. ${ }^{1,2}$ In dogs, cats, rabbits, and monkeys, they showed that phenobarbital prevented and treated the convulsions produced by cocaine overdose. Although Knoefe ${ }^{3}$ and Steinhaus ${ }^{4}$ were unable to reproduce these results, the cautious use of barbiturates is still recommended to prevent or control convulsions produced by local anaesthetics in man. ${ }^{5}$

Moore ${ }^{\mathbb{b}}$ reported on the usefulness of oxygen as an antidote to prevent this complication. He treated patients with oxygen and the muscle relaxant succinylcholine to obviate seizures once the early signs of confusion, nausea and vomiting, increased respiratory activity, blood pressure rise, and tachycardia occurred. He indicated that because they masked the warning signs and further promoted cardiorespiratory collapse barbiturates were dangerous. On the other hand, Usubiaga et al. ${ }^{7}$ illustrated in man that high levels of procaine prolonged the duration of action of succinylcholine in low concentration by freeing it from plasma protein, but in higher concentrations it probably interfered competitively with its hydrolysis by pseudocholinesterase. The same group of investigators observed that succinylcholine did not alter the EEG spikes typical of convulsions, but merely blocked endplate depolarization, thus negating the motor sequelae of CNS activity. ${ }^{8}$ From these conclusions it is inferred that the role of succinylcholine in local anaesthetic toxicity is to facilitate airway procurement during violent seizures, a contention of certain danger if used by the inexperienced. ${ }^{5}$

It appears that ultrashort acting barbiturates may still have a place in symptomatic relief of this type of convulsion in man. Adriani ${ }^{\theta}$ suggested that under these circumstances such drugs ought to be used with caution when cardiorespiratory depression is present. Remmer ${ }^{10}$ proposed that the prior injection of phenobarbital in addition to CNS antagonism promoted the liver microenzyme systems and therefore, by induction of a "procainesterase" system, it would decrease the duration of toxic symptoms. In another study, barbital and phenobarbital shortened the duration of toxicity produced by lidocaine in mice, while ethionine inhibited these effects. ${ }^{11}$ These latter two actions may actually play a minor role in the prevention or treatment of drug-induced convulsions.

Previous studies combining inhalation agents with toxic doses of local anaesthetic drugs were discouraging. Wood and Haggart ${ }^{12}$ showed in mice and dogs that ether, chloroform, and cyclopropane potentiated the effects of cocaine, pro-

-Department of Anesthesiology, University of Miami School of Medicine, P.O. Box 875, Biscayne Annex, Miami, Florida. 
caine, and lidocaine, apparently reducing the LD-50 significantly by an additive depressive effect on the cardiorespiratory system, while at the same time convulsions were non-apparent. The protecting effect that recently introduced agents might have on the CNs toxicity produced by local anaesthetics has not been investigated. The purpose of this study was to determine whether one or all of these agents might have a protective or detrimental action in the neurological toxicity of overdose of local anaesthetics.

\section{Materials and Methods}

Male Sprague-Dawley albino rats weighing from $65-90 \mathrm{gm}$ were used. The intraperitoneal $\mathrm{LD}-50$ doses of procaine, lidocaine, and tetracaine were determined using 20 rats per agent. They were found to be $230 \mathrm{mg} / \mathrm{kg}$ for procaine, $100 \mathrm{mg} / \mathrm{kg}$ for lidocaine, and $30 \mathrm{mg} / \mathrm{kg}$ for tetracaine. With these dosages, 80 per cent of the rats convulsed. The two main observations made throughout the study were duration of seizure measured by obvious grand mal activity and time from injection to death as noted by absence of respiratory and cardiac activity. Gases were delivered at constant flows into a chamber containing the rats, as described elsewhere. ${ }^{13}$ The animals were kept in this chamber 30 minutes and then injected and replaced in a different chamber into which the same gases were delivered. The oxygen concentration of both chambers was kept constantly at 21 per cent $\left(\mathrm{P}_{\mathrm{O}_{2}} 126\right)$ by measuring it at the bottom of the chambers with a Beckman Oximeter. When only oxygen was used, the $\mathrm{P}_{\mathrm{O}_{2}}$ in the chamber was $514 \mathrm{~mm} \mathrm{Hg}$. A Mayo gas vapour analyser was employed to measure the percentage concentration of halothane, methoxyflurane, and fluoroxene.

It was intended to deliver $1.3 \mathrm{MAC}$ to the chamber in the experiments with high concentrations and $0.3 \mathrm{MAC}$ to the chamber in those experiments with low percentages. Twenty-four rats were employed for each of the twelve experiments. Each of four groups of six rats was injected with one of the three local anaesthetic agents or saline. The gases employed in this experiment were air, 100 per cent $\mathrm{O}_{2}, \mathrm{~N}_{2} \mathrm{O}-\mathrm{O}_{2}$ in 4:1 ratio, and halothane, methoxyflurane, and fluroxene vaporized in a mixture of nitrous oxide and oxygen to contain 21 per cent of the latter gas. The room temperature was kept constant at $24^{\circ} \mathrm{c}$. The total flow was $5 \mathrm{~L} / \mathrm{min}$. in all experiments.

\section{RESUlts}

Rats inhaling oxygen and air exhibited no abnormal behaviour. When high concentrations of anaesthetic agents were given, the rats were asleep within 15 minutes. Those animals breathing $\mathrm{N}_{2} \mathrm{O}-\mathrm{O}_{2}$ and low percentages of volatile agents were excited and agitated before injection. After injection of local anaesthetics, they were ataxic and unable to right themselves. Myoclonic activity preceded grand mal seizures, although not all animals who were myoclonic convulsed. Some, but not all, of those injected animals had tachypnoea and hyperpnoea. Apnoea usually preceded death. The results are summarized in Table I. 


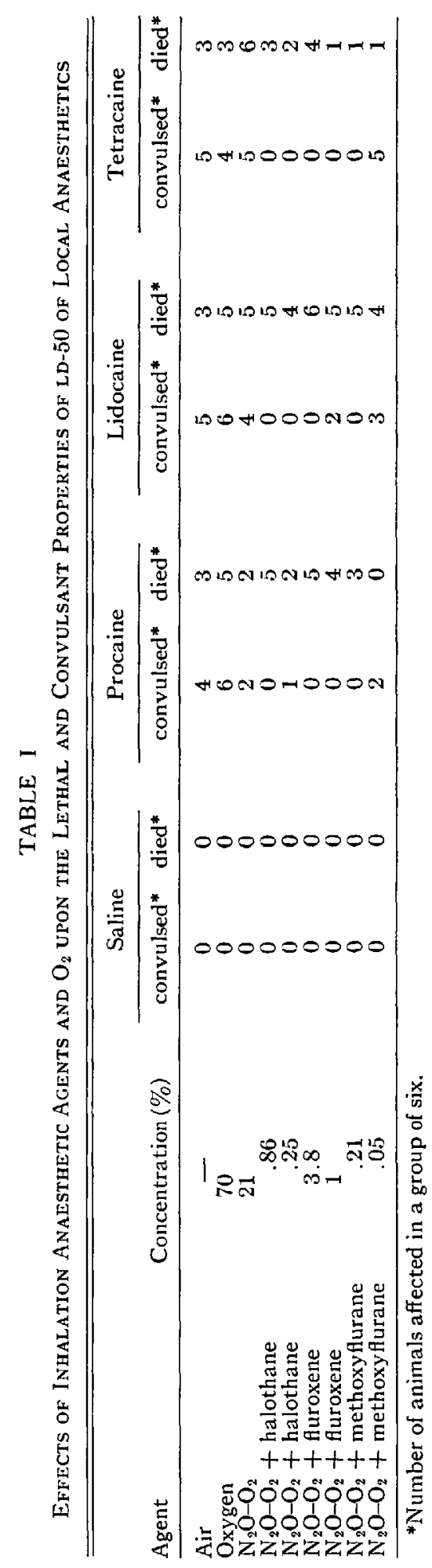




\section{Discussion}

Statistically, in this study, $\mathrm{O}_{2}, \mathrm{~N}_{2} \mathrm{O}-\mathrm{O}_{2}$, or the various inhalation agents regardless of concentration did not significantly guard against the lethal complications of local anaesthetic toxicity comparatively observed when air was inhaled by rats. Although high percentages of halothane, methoxyflurane, and fluroxene appeared to reduce the convulsive activity seen, this is a moot point. The results suggested that these agents increase the lethal effects of local anaesthetic agents. With concentrations of $1 \frac{1}{3} \mathrm{MAC}$, the results were similar to those of Wood and Haggart, ${ }^{12}$ who noted that inhalational agents ablate obvious convulsions, but increase lethal complications by summation effects with local anaesthetic drugs, depressing the cardiorespiratory system. When low concentrations of methoxyflurane were inhaled, the administration of all local anaesthetic agents showed a reduced lethal potential. Specifically, with low percentages of fluroxene and halothane, tetracaine appeared to be less toxic. It could be hypothesized that there is a dual action of these agents depending on concentration; at high percentages, the convulsant effects of toxic levels of local anaesthetic drugs might be antagonized by suppression of the trigger zone of the CNs, located in the amygdalar ${ }^{14}$ region of the rhinencephalon, but this suppression also affects the respiratory centre which, combined with the already present suppression produced by local anaesthetic agents, results in apnoea and eventually death. This was further demonstrated in the rats breathing high oxygen concentrations, which showed no protection by this gas alone. Therefore, its alleged beneficial effects shown in other studies ${ }^{6,15}$ might be due to the fact that ventilatory exchange was maintained.

It can only be inferred that at low concentrations the trigger zone is suppressed, while the additive detrimental effect on respiratory and cardiac functions does not reach lethal potency, thus resulting in relative protection from toxicity.

In an analogous situation, Richards et al. ${ }^{16}$ showed in mice that the protective range of pentobarbital is narrow. The LD -50 of lidocaine was lowered by concentrations of pentobarbital greater than $40 \mathrm{mg} / \mathrm{kg}$. No change was noted with less than $20 \mathrm{mg} / \mathrm{kg}$. However, protection was achieved with dosages between 20 and $40 \mathrm{mg} / \mathrm{kg}$. This dual effect on the LD-50 of lidocaine by pentobarbital can be interpreted as protection against convulsions at intermediate doses, and a combined barbiturate-local anaesthetic depression on cardiorespiratory functions at higher concentrations. Perhaps a more careful titration of anaesthetic agent concentration might better protect against convulsive and lethal effects of local anaesthetics.

\section{SUMMARY}

The inhalation of low concentrations of anaesthetic mixtures by rats appeared to provide protection from the obvious convulsions produced by intraperitoneal injections of L.D-50 doses of local anaesthetic drugs. However, higher concentrations enhanced the lethal effects of procaine, lidocaine, and tetracaine, probably by a summation of their depressive action on the cardiac and respiratory functions. 


\section{RÉSUMÉ}

L'inhalation par des rats de faibles concentrations de mélanges gazeux anesthésiques a semblé procurer à ces animaux une protection contre les convulsions évidentes produites par les injections LD-50 intrapéritonéales d'anesthésiques locaux. Cependant, de plus fortes concentrations ont augmenté les effets mortels de la procaïne, de la lidocaïne, de la tétracaïne, probablement par l'addition de leur action dépressive sur les fonctions cardiaques et respiratoires.

\section{REFERENCES}

1. Tatum, A. L. ; Atrinson, A. J.; \& Collins, K. H. Acute Cocaine Poisoning: Its Prophylaxis and Treatment in Laboratory Animals. J. Pharmacol. \& Therap. 26: 325 (1925).

2. Tatum, A. L. \& Collins, K. H. Acute Cocaine Poisoning and Its Treatment in Monkeys (Macacus Rhesus). Arch. Int. Med. 38: 405 (1926).

3. Knoffel, P. K.; Menwich, R. P.; \& Lovenhurt, A. S. Prevention of Acute Intoxication from Local Anaesthetics. J. Pharmacol. \& Therap. 39: 397 (1930).

4. Steinfraus, J. E. Comparative Study of Experimental Toxicity of Local Anesthetic Agents. Anesthesiology. 13: 577 (1952).

5. Adriani, J. Barbiturates Combined with Local Anesthetics. Anesthesiology. 29: 405 (1968).

6. Moore, D. C. \& Bridenbaugh, L. D. Oxygen: The Antidote for Systemic Toxic Reactions from Local Anesthetic Drugs. J.A.M.A. 174: 842 (1960).

7. Usubiaga, J.; Wikinskr, J. A.; Morales, R. L.; \& Usubiaga, L. E. J. Interaction of Intravenously Administered Procaine, Lidocaine and Succinylcholine in Anesthetized Subjects. Anesth. \& Analg. 46: 39 (1967).

8. Usubiaga, J.; Wikinski, J.; Ferrero, R.; Usubiaga, L. E.; \& Wikinski, R. Local Anesthetic Induced Convulsions in Man: An Electroencephalographic Study. Anesth. \& Analg. 45: 611 (1966).

9. Adriani, J. Absorption and Systematic Toxicity of Local Anesthetics. G.P. 25: 82 (1962).

10. Remmer, H. \& Mekeker, H. J. Morphological Changes in Endoplasmic Reticulum of the Liver Cells with Enzyme Induction after Pretreatment with Several Drugs. Biochem. Pharmacol. 12: 78 (1963).

11. Heinonen, J. The Effects of Drugs on the Duration of Toxic Symptoms Caused by Sublethal Doses of Local Anesthetics: An Experimental Study on Mice. Acta. Pharmacol. et Tox. 21: 155 (1964).

12. Woons, L. A. \& HaGGart, J. Apneic and Hypotensive Effects of Local Anesthetic Drugs in Dogs and Mice under General Anesthesia. Anesthesiology. 18: 831 (1957).

13. Aldrete, J. A. \& Jondan, C. A Chamber for the Chronic Exposure of Small Animals to Anesthetic Gases. Anesthesiology. 32: 464 (1970).

14. Elliot, M. W.; Qumici, G. C.; \& Elizison, C. Central Effects of Local Anesthetics. Fed. Proc. 19: 274 ( 1960).

15. Daoz, F. G.; Lopez, L.; \& Virtue, R. W. Local Anesthetic Toxicity Modified by Oxygen and by Combination of Agents. Anesthesiology. 23: 755 (1962).

16. Richard, R. K.; Smith, N. T.; \& KatZ, J. The Effects of Interaction between Lidocaine and Pentobarbital on Toxicity in Mice and Guinea Pig Atria. Anesthesiology. 29: 493 (1968). 